\title{
Structural Studies of Rare Earth-doped Fluoroborosilicate Glasses by Advanced Solid-state NMR
}

\author{
Xuyang Zhang, ${ }^{\text {ab }}$ Lili Hu, ${ }^{\text {ab }}$ Jinjun Ren*ab \\ ${ }^{a}$ Key Laboratory of Materials for High Power Laser, Shanghai Institute of Optics and Fine Mechanics, Chinese Academy of \\ Sciences, Shanghai 201800, P. R. China \\ ${ }^{\mathrm{b}}$ Center of Materials Science and Optoelectronics Engineering, University of Chinese Academy of Sciences, Beijing 100049, \\ P.R. China \\ *Email: renjinjunsiom@163.com
}

\section{Fluorine Quantification}

The fluoride/oxide exchange ineluctably occurs during the high temperature glass melting process, resulting in large difference between the nominal fluorine contents and the real residual ones. This problem can be resolved by ${ }^{19} \mathrm{~F}$ rotor-synchronized spin echo NMR method, using $\mathrm{BaF}_{2}$ as an internal quantification standard. The ${ }^{19} \mathrm{~F}$ spectra were acquired by spin echo pulse rather than single-pulse, aiming at obtaining a better baseline. Considering the effect of evolution time, two individual experiments were conducted for each sample, with the $\pi$ pulse located after one and two rotor periods. In addition, since the relaxation delay required for full relaxation for $\mathrm{BaF}_{2}$ crystal is too long $(500 \mathrm{~s})$, the relaxation delay of $60 \mathrm{~s}$ for glass samples was used in the following quantification experiments. For a clear peak deconvolution, each glass sample and $\mathrm{BaF}_{2}$ standard were mixed with the nominal $\mathrm{F}$ molar ratio of 4:1. Figure $\mathrm{S} 1$ (a) shows the comparison of ${ }^{19} \mathrm{~F}$ single-pulse spectra of $\mathrm{BaF}_{2}$ at the relaxation delays of 60 and $500 \mathrm{~s}$, respectively. Figure S1 (b) shows the representative quantification result of $60 \mathrm{Si}-10 \mathrm{~B}$ glass. The narrow signal of the BaF $\mathrm{standard}_{2}$ appears at $-13.7 \mathrm{ppm}$. The spectra are deconvoluted into Gauss/Lorentz curves, using the DMFIT package. ${ }^{1}$

The intensity $I_{0}$ is obtained from $I_{1}$ (one rotor period) and $I_{2}$ (two rotor periods),

$I_{0} / I_{1}=I_{1} / I_{2}=f$

Thus, the intensity

$I_{0}=I_{1} \times f$

Considering the incomplete relaxation of $\mathrm{BaF}_{2}$,

$I_{B a F_{2}}=I_{0\left(B a F_{2}\right)} \times\left(I_{500 s} / I_{60 s}\right)$

Here, $I_{500 \mathrm{~s}}$ and $I_{60 \mathrm{~s}}$ are obtained from single-pulse spectra, as shown in Figure S1 (a).

Therefore, the residual $\mathrm{F}$ fraction,

$F=\left(I_{1(F-B)} \times f_{F-B}+I_{1(F-Y 1)} \times f_{F-Y 1}+I_{1(F-Y 2)} \times f_{F-Y 2}\right) / I_{B a F_{2}} \times 4 \approx 36 \%$ 


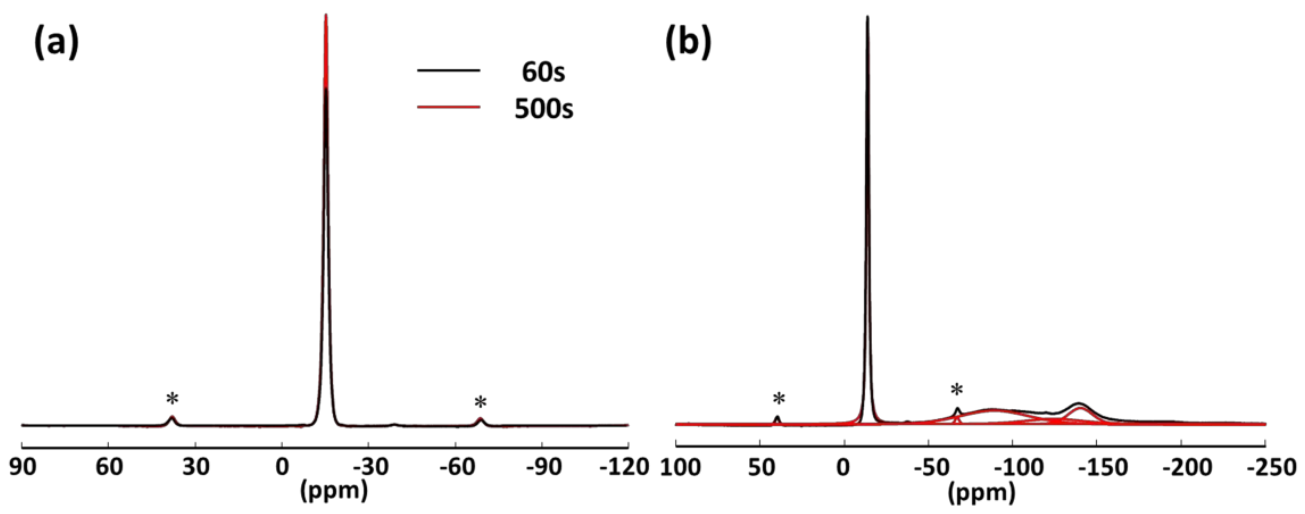

Figure S1. (a) ${ }^{19} \mathrm{~F}$ single-pulse spectra of $\mathrm{BaF}_{2}$ at the relaxation delays of 60 and $500 \mathrm{~s}$, respectively. (b) ${ }^{19} \mathrm{~F}$ rotor-synchronized spin echo spectra of $60 \mathrm{Si}-10 \mathrm{~B}$ glass and $\mathrm{BaF}_{2}$ standard with the nominal $\mathrm{F}$ molar ratio of $4: 1$. Line shape deconvolution components are displayed by red curves, and their sum is displayed by the black curve. Spinning sidebands are denoted by asterisks.

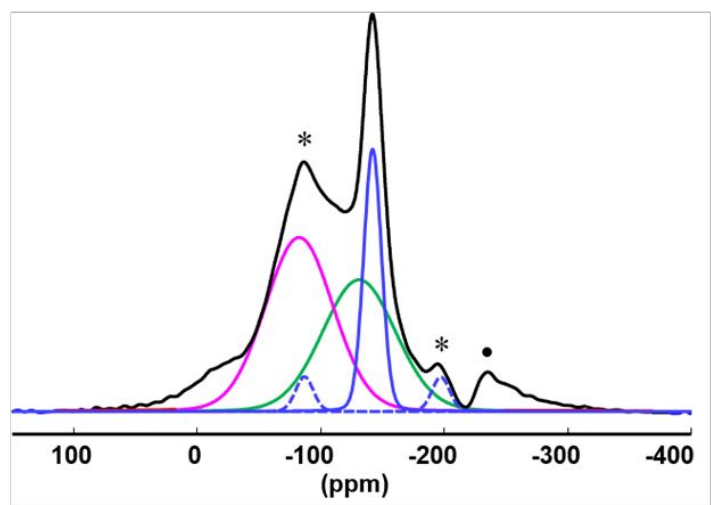

Figure S2. Representative deconvolution result of ${ }^{19} \mathrm{~F}$ MAS NMR spectrum of 65Si-5B glass. The pink, green, and blue solid lines denote $\mathrm{Na}-\mathrm{F}-\mathrm{Y} 1, \mathrm{Na}-\mathrm{F}-\mathrm{Y} 2$, and $\mathrm{Na}-\mathrm{F}-\mathrm{B}$ linkages, respectively. The dotted blue lines denote spinning sidebands of Na-F-B linkages, which are indicated by asterisks. The solid circle represents probe background.

Table S1. Deconvolution of ${ }^{19}$ F MAS NMR Spectra of All the Glasses

\begin{tabular}{lllllc}
\hline samples & & $\begin{array}{l}\delta_{C S}{ }^{i s o}(\mathrm{ppm}) \\
( \pm 0.5 \mathrm{ppm})\end{array}$ & $\begin{array}{l}F W H M(\mathrm{ppm}) \\
( \pm 0.5 \mathrm{ppm})\end{array}$ & fraction $(\%)( \pm 10 \%)$ \\
\hline 50Si-20B & $\mathrm{Na}-\mathrm{F}-\mathrm{Y} 1$ & -75.3 & 54.1 & 54.3 & 66.8 \\
& $\mathrm{Na}-\mathrm{F}-\mathrm{Y} 2$ & -150.2 & 75.3 & 12.5 & \\
& $\mathrm{Na}-\mathrm{F}-\mathrm{B}$ & -144.3 & 17.5 & 33.2 & \\
& $\mathrm{Na}-\mathrm{F}-\mathrm{Y} 1$ & -78.5 & 55.0 & 51.3 & 71.1 \\
& $\mathrm{Na}-\mathrm{F}-\mathrm{Y} 2$ & -145.5 & 75.4 & 19.8 & \\
& $\mathrm{Na}-\mathrm{F}-\mathrm{B}$ & -143.3 & 17.5 & 28.9 & \\
& $\mathrm{Na}-\mathrm{F}-\mathrm{Y} 1$ & -83.5 & 55.0 & 48.6 & 74.2 \\
& $\mathrm{Na}-\mathrm{F}-\mathrm{Y} 2$ & -140.1 & 75.4 & 25.7 & \\
\hline
\end{tabular}




\begin{tabular}{llllll}
\hline & Na-F-B & -143.5 & 17.5 & 25.8 & \\
65Si-5B & Na-F-Y1 & -82.5 & 65.0 & 43.0 & 78.3 \\
& Na-F-Y2 & -131.1 & 75.4 & 35.3 & \\
& Na-F-B & -142.0 & 17.3 & 21.7 & \\
\hline
\end{tabular}

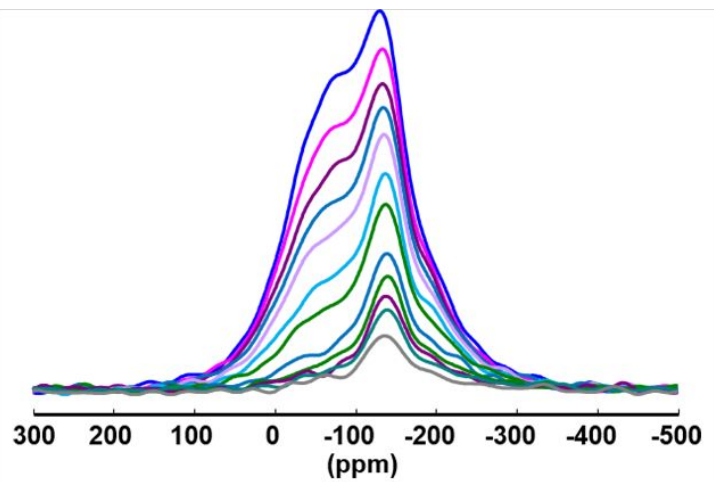

Figure S3. ${ }^{19} \mathrm{~F}$ static spin echo spectra of 50Si-20B glasses at different dipolar mixing times $(20,30,40,50,60,80,100,150,200,250,300$, and $400 \mu \mathrm{s})$.

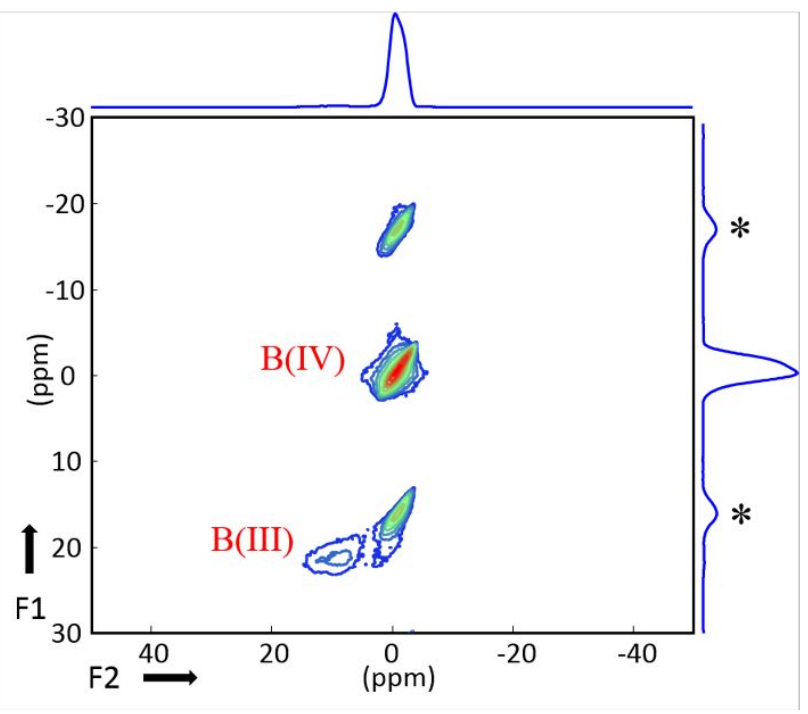

Figure S4. ${ }^{11} \mathrm{~B}$ TQMAS NMR spectra of 55Si-15B glass. 


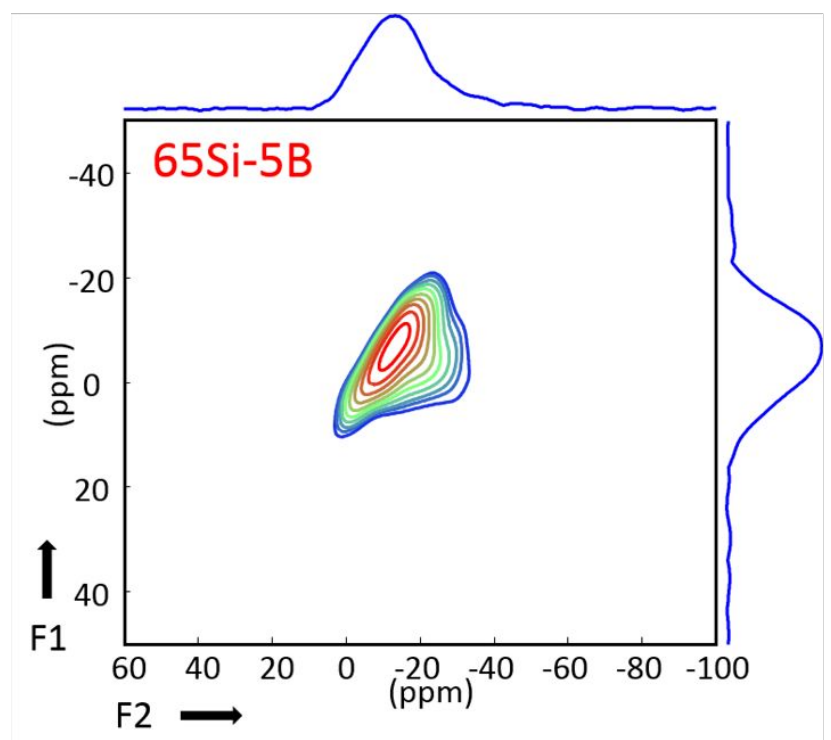

Figure S5. ${ }^{23} \mathrm{Na}$ TQMAS NMR spectra of 65Si-5B glass.

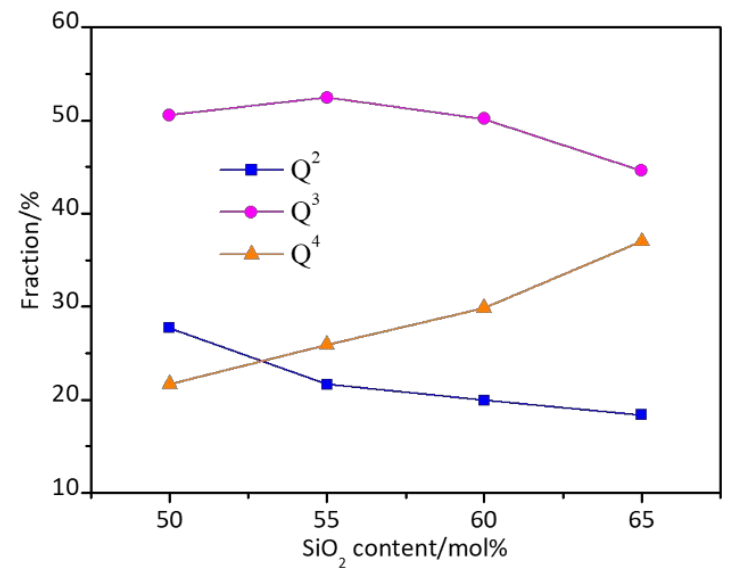

Figure S6. The fraction evolution of $\mathrm{Q}^{\mathrm{n}}$ units with the increase of $\mathrm{SiO}_{2}$ content.

\section{REFERENCES}

1. Massiot, D.; Fayon, F.; Capron, M.; King, I.; Le Calvé, S.; Alonso, B.; Durand, J. O.; Bujoli, B.; Gan, Z. H.; Hoatson, G. Modelling One- and Two-dimensional Solid-state NMR Spectra. Magn. Reson .Chem. 2002, 40, 70-76. 